\title{
Adaptive Platforms and Flexible Deposition System for Big Area Additive Manufacturing (BAAM)
}

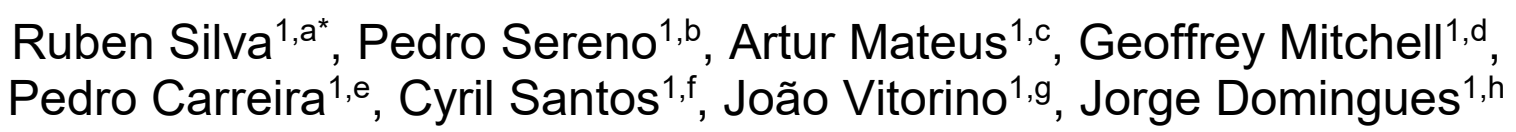

\author{
${ }^{1}$ Centre for Rapid and Sustainable Product Development - IPL, Portugal \\ aruben.j.silva@ipleiria.pt, bpedro.sereno@ipleiria.pt, cartur.mateus@ipleiria.pt, \\ dgeoffrey.mitchell@ipleiria.pt, epedro.s.carreira@ipleiria.pt, ${ }^{\mathrm{f}} \mathrm{cyril}$. santos@ipleiria.pt, \\ gjoao.vitorino@ipleiria.pt, hjorge.m.domingues@ipleiria.pt
}

${ }^{*}$ corresponding author

\begin{abstract}
Keywords: Additive Manufacturing; Big Area Additive Manufacturing; Hybrid Manufacturing; Ecological; Concrete; Tires; Automobile; Circular Economy.
\end{abstract}

\begin{abstract}
The interest around the additive manufacturing is increasing, with more and more solutions at both the industrial and desktop levels. As this is still a relatively recent issue for several industrial areas, there is a clear opportunity to explore in order to optimize the systems in the face of the needs of these same industries, and with increasing times, there are increasing factors to take into ac- count in initial phases of new product development. Presently, there is also a growing ecological awareness, with the concern of implementing a logic of waste reduction and implementation of the circular economy in new products with a view to the valuation of new alternative materials. With the development of solutions aimed at the optimization and feasibility of large additive manufacturing systems, the introduction of new alternative materials will be a reality, presenting in this article a solution and methodology for future tests for new materials. Thus, herein is studied a way of responding to both problems, new ecological materials and BAAM system optimization, presented through a hybrid and flexible solution based on the Pin Bed Forming principle applied to Big Area Additive Manufacturing systems.
\end{abstract}

\section{Introduction}

There is a growing interest in AM technologies which has aroused interest and fostered development around cross-cutting aspects of the technology, for example to create new possibilities and advantages in the design of parts, development of different additive processes and above all the rising number of materials and its properties that the technology allows to produce.

Several authors identify the development of additive manufacturing behind the new industrial revolution allied to a substantial growth of the AM technology market share [1,2]. By 2014 it was projected that the additive manufacturing market, in 2016, would worth around $\$ 5$ billion, for assessed in 2013 in the industry worth of $\$ 3.07$ billion at the time. A 2016 report shows how the AM industry effectively surpassed forecasts of $\$ 5$ billion, thus a year before the expected $[3,4,5]$.

There is need for innovation and development in AM systems in order to bring industrial sustainability to additive processes, with aim for in house production so this technology isn't viewed as a hyped subject associated with risks but as a "must have" in order to expand companies and target new markets. Latest report on the AM industry, according to Wohlers Associates [4] "2016 represents a slowdown in the industry's expansion after a six-year growth trend of 24-35\% each year. Weak performance of 2016 by the two largest companies in the business. "(P.144)

This article will analyze various aspects, problems and propose solutions related to the additive manufacturing system as a whole, applied in the production of large parts. How to take advantage of new materials and an incorporation of the model of circular economy aiming its increased value. This article also covers problems and solutions, regarding the need for support material and its implications for Big Area Additive Manufacturing (BAAM). 


\section{Additive Manufacturing}

History. Although additive manufacturing has been around for 30 years, only in 2009 the patent for fused deposition modeling (FDM) which made the technology available to the public. This finally allowed new research and development on the technology without involving legal affairs. This makes the AM industry very young which creates more opportunities to develop new systems with new materials for new applications.

The first work with modern photolithographic AM system was conceptualized in 1970's by Swainson who patented a system which produced solid geometries from the intersection of radiation beams. Later in 1980 the idea was abandoned due to the lack of funds, without achieving good results in final models due to the lack of development on parameters and photosensitive materials [6].

In 1984, Charles W. Hull created and patented the first modern additive manufacturing system, the Stereolithography Apparatus (SLA). As expected, this technology came out too expensive for the general industry and didn't earn much attention as its potential wasn't fully recognized [2].

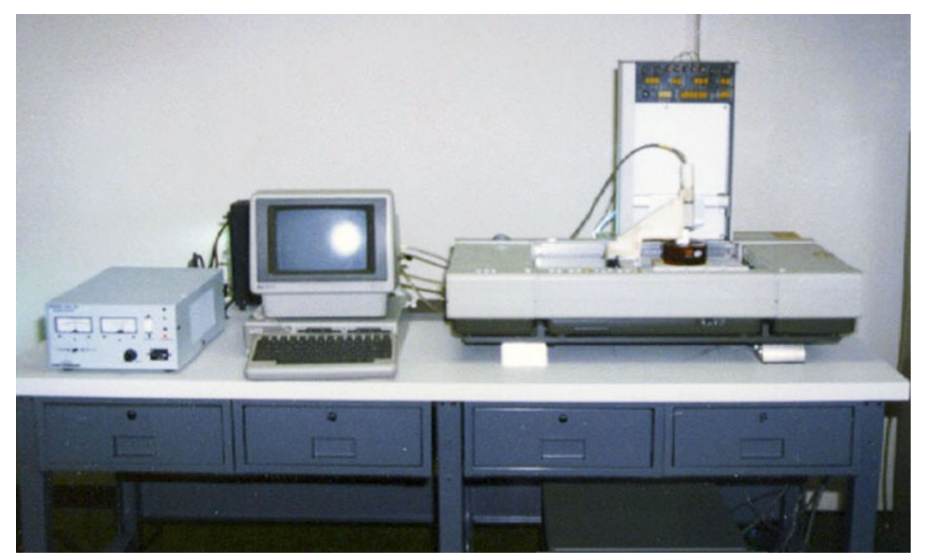

Fig. 1 - The Stereolithography Apparatus by Charles W. Hull [2]

The additive manufacturing concept starts with a CAD software where a part can be created with a defined geometry and then exported as a STL file (STereoLithography) readable by AM systems. The additive system will translate sliced part to be produced in a layer-by-layer basis, similar to standard inkjet printing but layering materials instead of inks [7,6].

In 1989 a patent on Fused Deposition Modeling (FDM) was filled by the self-proclaimed inventor and co-founder of Stratasys, Ltd, Steven Scott Crump alongside with his wife and also Stratasys co-founder Lisa Crump [8].

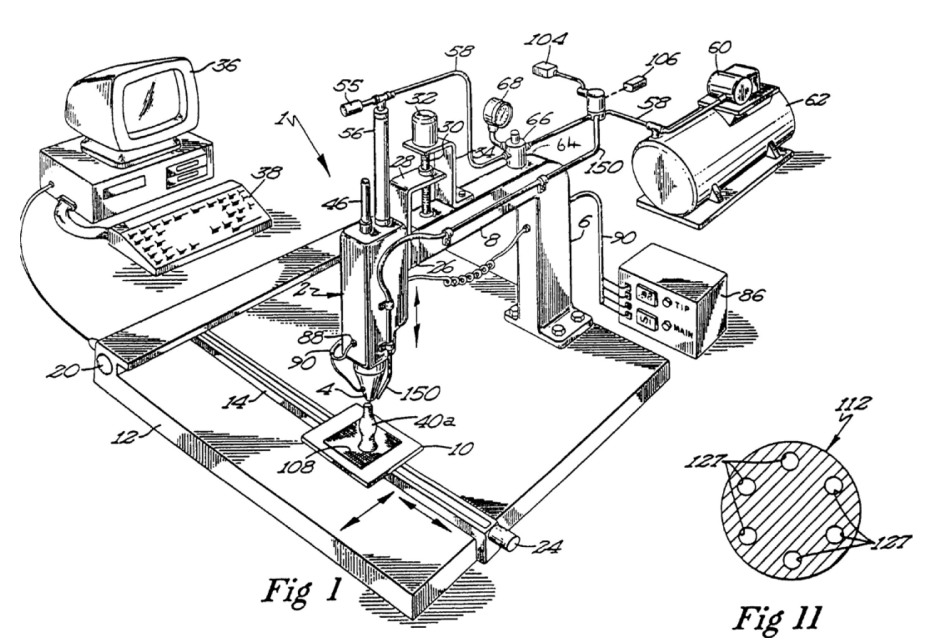

Fig. 2 - Fused Deposition Modeling system by Steven S. Crump [8] 
Also, during the 1980's, the idea of directing a laser or electron beam to heat- fusible powders originated the Selective Laser Sintering (SLS) process which is one of the most widely used. The patent was filled in 1990 and already scoped numerous materials [9] "examples of the types of powders include metal powders, polymer powders such as wax that can be subsequently used in investment casting, ceramic powders, and plastics such as ABS plastic, polyvinyl chloride (PVC), polycarbonate (PC) and other polymers." (p.1)

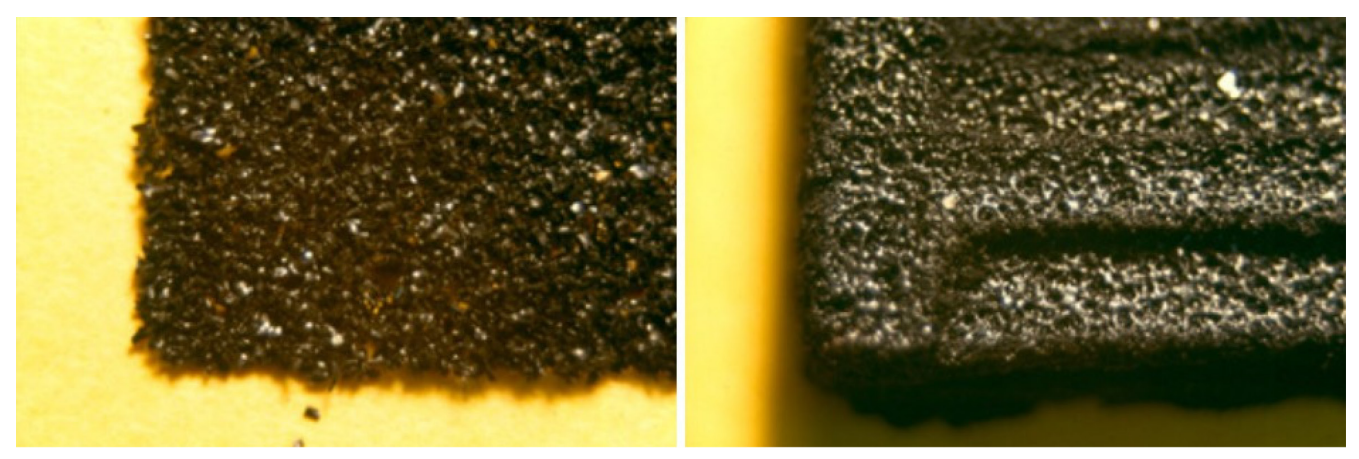

Fig. 3 - Before and after, produced by Betsy SLS system [9]

Between 1980's and 1990's there was more patents being filled and academic re- search on the subject, however the technology was high cost, had few material options and most industrial applications such as model making, or prototyping were limited by its low dimensional accuracy.

The next decade was a great period for AM, between 1990s and 2000s it was developed new processes, new materials and improved technologies which brought more attention and new potential, but softwares were lacking improvements. During this period there was more efforts on developing new software in order to improve the overall quality of AM systems. By that time, 'Rapid Manufacturing', 'Rapid Casting' and 'Rapid Tooling' were terms created to refer to the usage of AM [10].

It was finally in the 2000s that the AM market became more competitive. Major patents expired, most softwares and processes were further developed, optimized and the growth of metal-based additive processes shown that AM is here to stay. The technology was ultimately available to the masses, creating a hobby community that fostered the general interest. Parallel to this, some industries implemented AM processes do deliver final product to customers in such areas as dental, medical and aerospace industries [11].

Big Area Additive Manufacturing: State of the Art. Big Area Additive Manufacturing brings new possibilities and the potential to be widely accepted by the industry. The ability to reduce manufacturing lead times, stocks and create customized parts on demand are a few of the advantages related to AM technologies.

There's been already a few systems developed for Big Area Additive Manufacturing (BAAM) and those considered more relevant are the D-shape, developed and patented by Monolite UK, and ORNL's (Oak Ridge National Laboratories) BAAMCi system, sponsored by U.S. Department of Energy in con-jointed efforts with Cincinnati Inc. These two systems operate with completely diferent technologies: D-Shape uses a powder bed with a binder jet and BAAMCi system works with fused deposition modeling (FDM). Althought both technologies already find their place in the market for smaller systems, these bigger ones are scoped for actual industrial production and don't compete directly with each other.

ORNLs BAAMCi system features a few interesting solutions: A problem found during its development was related with the material deposition causing distortion and warping. The fact the printer has an open build envelope without a thermal- controlled environment proposes the resort of materials with low coefficient of thermal expansion (CTE). The main tested materials for BAAMCi are stated accordingly to [12] "from acrylonitrile butadiene styrene (ABS), to polyphenylene sulfide (PPS), to polyether ether ketone (PEEK) and many others" (p.2). 

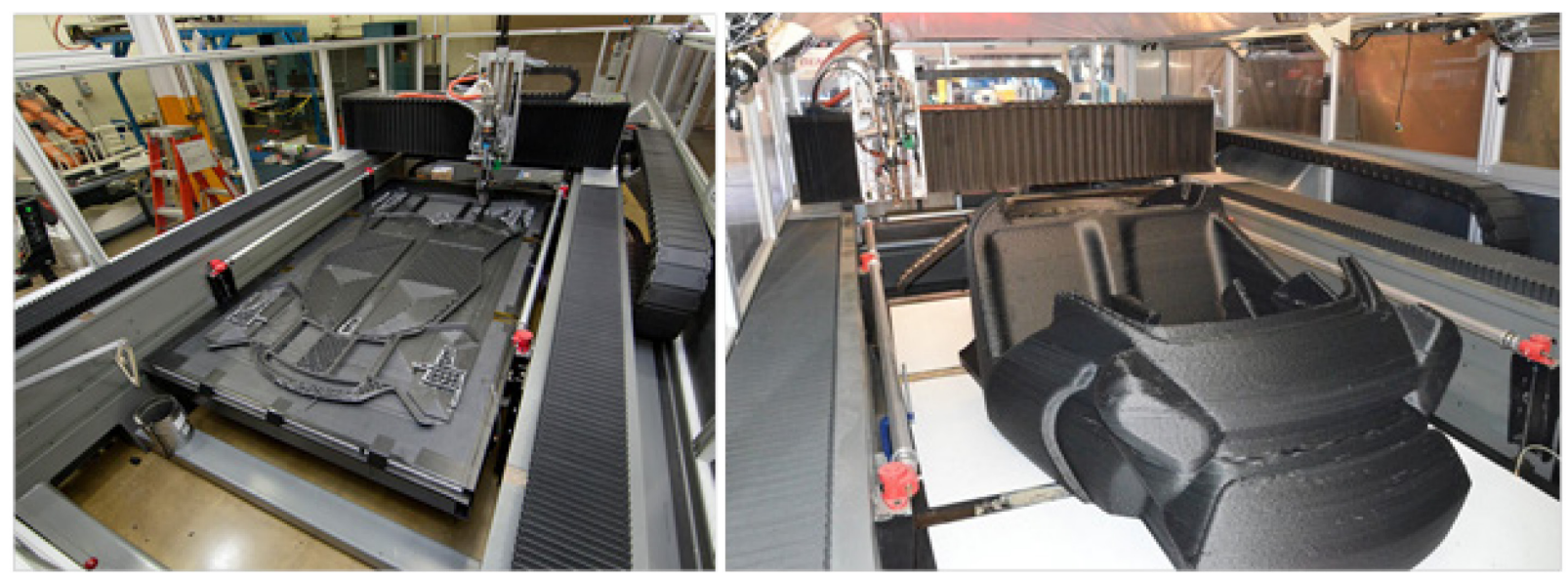

Fig. 4 - BAAMCi AM system by ORNL and Cincinnati [13]

BAAMCi uses reinforced polymers as a solution to distortion and warping problems and also as a performance factor for its produced parts. Another key solution later tested by proposes infrared preheating of the surface to be printed on increasing the surface adhesion and preventing related defects. The work results shown a significantly increases in surface adhesion and overall part quality therefore, big area additive manufacturing using fiber reinforced thermoplastics can really benefit with the advantages of coupling a preheating system [13].

Monolite Uk's D-shape features a different technology and was developed with a different aim. It focus on producing conglomerate structures for house building. The development started in 2007 and Its patent was filled in 2010 and it was developed from Enrico Dini for the Minister of Defense in Italy. The project aimed to build shelters for troops using reinforced materials strong against ballistics. D-shape works with binder jet technology applied to a big area. Its printhead consists of high pressure nozzles that pulverizes the binder on to the powder. This powder contains a catalyst in which reacting with the binder builds the solid structure after its rest. After the removal of the excess powder the part can be post-processed and most of the removed powder can be reused [14].
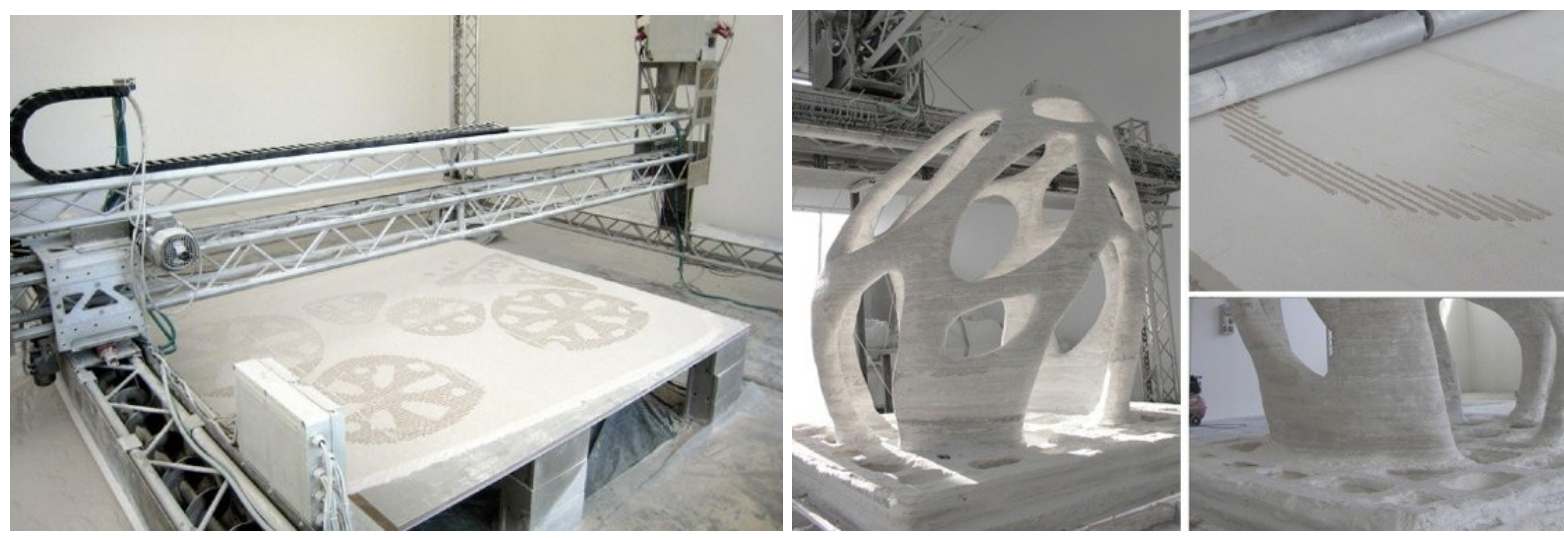

Fig. 5 - D-Shape AM system by Enrico Dini and Monolite UK, Ltd

Both of these technologies are the best suited for BAAM processes. Both systems require post processing to ensure the high-quality finishing depending on its application. The D-shape system allows a wider range of materials and easily permits the inclusion of a circular economy model in order to become more sustainable by decreasing material costs, at the same time it's providing new options with increased value on exploring new colors and textures, aesthetics and performance factors for new applications. 


\section{Materials}

Evolution. With the development of different additive manufacturing processes, there is a clear expansion of the range of solutions in terms of materials for these same processes. In the process of selection of materials for construction of a part through additive processes, the transparency that it offers, color, yield stress, rigidity, biocompatibility, glass transition temperature, resistance to moisture and resistance to flame [4].

Today, we can even see 4D printing of smart materials, having the capability to change their geometry by changing numerous stimulation factors [15], which can be an opportunity as it is possible do create big products by BAAM with 4D materials, offering new and innovative products in different areas or applications.

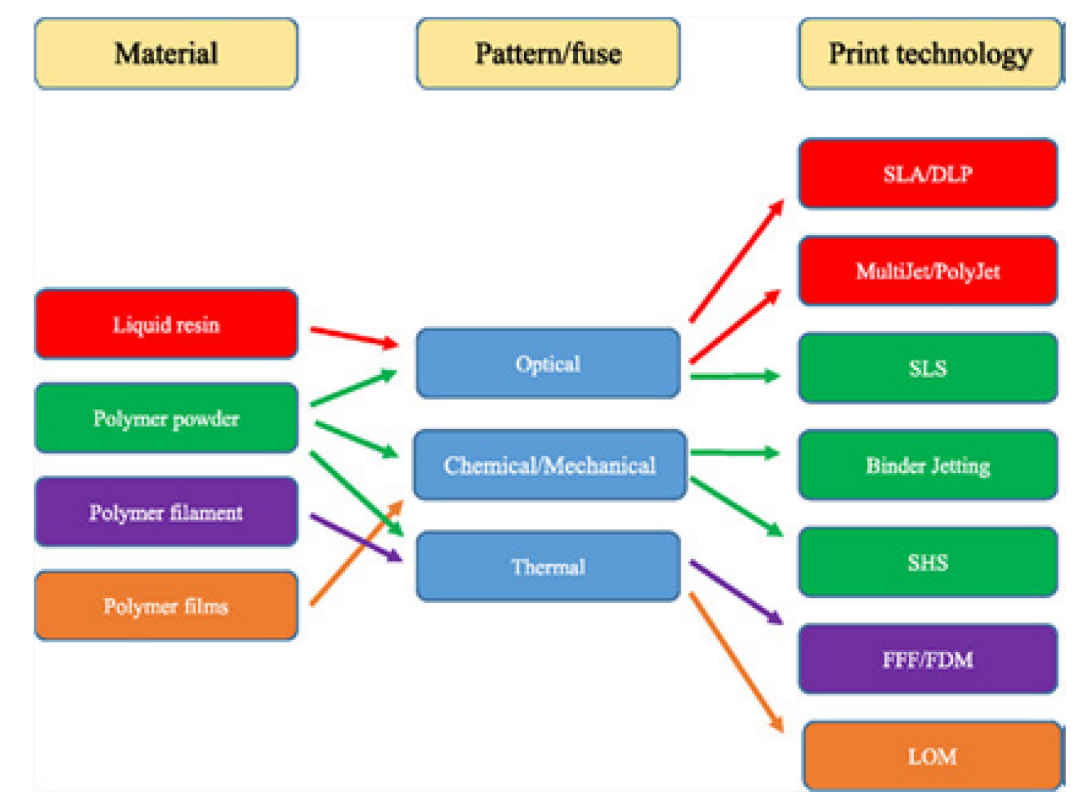

Fig. 6 - Materials and additive manufacturing technologies [16]

In addition to the factors mentioned above, it is still necessary to understand the process to be used and in what form the raw material is applied, and it is also necessary to understand if a particular raw material will be available in the form that the process is intended to be. In order to understand how these factors can be analyzed, a figure (Fig. 6) is shown [16], which diagram shows the different available forms of the raw material and related processes.

As an example, the FDM / FFF process, that until 2012 was limited to the supply of only ABS (Acrylonitrile Butadiene Styrene) and PLA (Polylactic Acid) filaments, it is currently possible to use HIPS (High Impact Polystyrene), PS (Polystyrene), PC (Polycarbonate), PET (Polyethylene Terephthalate), PVA (Polyvinyl alcohol), Nylon, and soft, rubber-like materials including TPU (Thermoplastic Polyurethane) and similar [17,16] There's also mineral and wood-fiber filled materials that allow the production of pieces with wood and stone appearance $[18,4]$.

In processes whose raw material is applied in powder form, the most common materials are polyamides (PA6, PA11, PA12), and materials such as PS, PP, as well as glass-, carbon- and aluminum-filled PAN. For more demanding applications in mechanical terms it is still possible to use PEEK, PEKK, among others. In these processes based on Powder Bed Fusion it is important to note that the unbound material during the process is approximated to its glass transition temperature, so for its reuse virgin raw material must be mixed in order to guarantee the integrity and original properties [16]. As for materials applied in photopolymerization processes, these are thermosets, usually acrylics, acrylates and epoxy, whose curing process is done through the application of UV radiation, some of these materials healing when exposed to light energy in the visible spectrum. This is a factor that has limitations in the transportation and storage of the material at the risk of making it unusable. In any of the previously presented materials there is currently a 
strong R \& D component from suppliers of various types of feedstock, resulting in new solutions at increasingly shorter intervals. With the development of technologies accessible to end users that can thus produce directly from their home, it is expected that the price of these raw materials will decrease dramatically, since it is currently one of the major constraints of these technologies, having as a comparison with the same raw materials applied, for example, to the injection of plastics, prices are about 20-100 times below the raw materials applied to the additive manufacturing [19].

\section{Big Area Additive Manufacturing (BAAM)}

In big area additive manufacturing (BAAM) technologies, polymeric materials such as glass fiber reinforced ABS were already tested, and the applications of PPS and PEKK were also studied. In these systems the raw materials in the form of pellets are used [12].

In a further aspect of BAAM, there are also advances in the construction of pieces based on the use of materials resulting from the exploitation of marble, among other stones [20], from which results the powder that is used in this process through the combination with a binder layer the layer forming complex parts [18] without the need to build specific tools such as molds, which generally make it economically unfeasible to construct parts of this type when dealing with small series production, while also reducing the waste generated with this specific tool construction [21].

Nowadays we see studies and developments at these kind of technologies, having as examples the production of a car named "Strati" (Fig. 7, left) which "was a four-and-a-half month process, from design to finish [12], but according to Rogers, the CEO of Local Motors, the company behind the Strati, the timescale for future models could be cut to as little as six weeks, and the printing itself to just 24 hours".
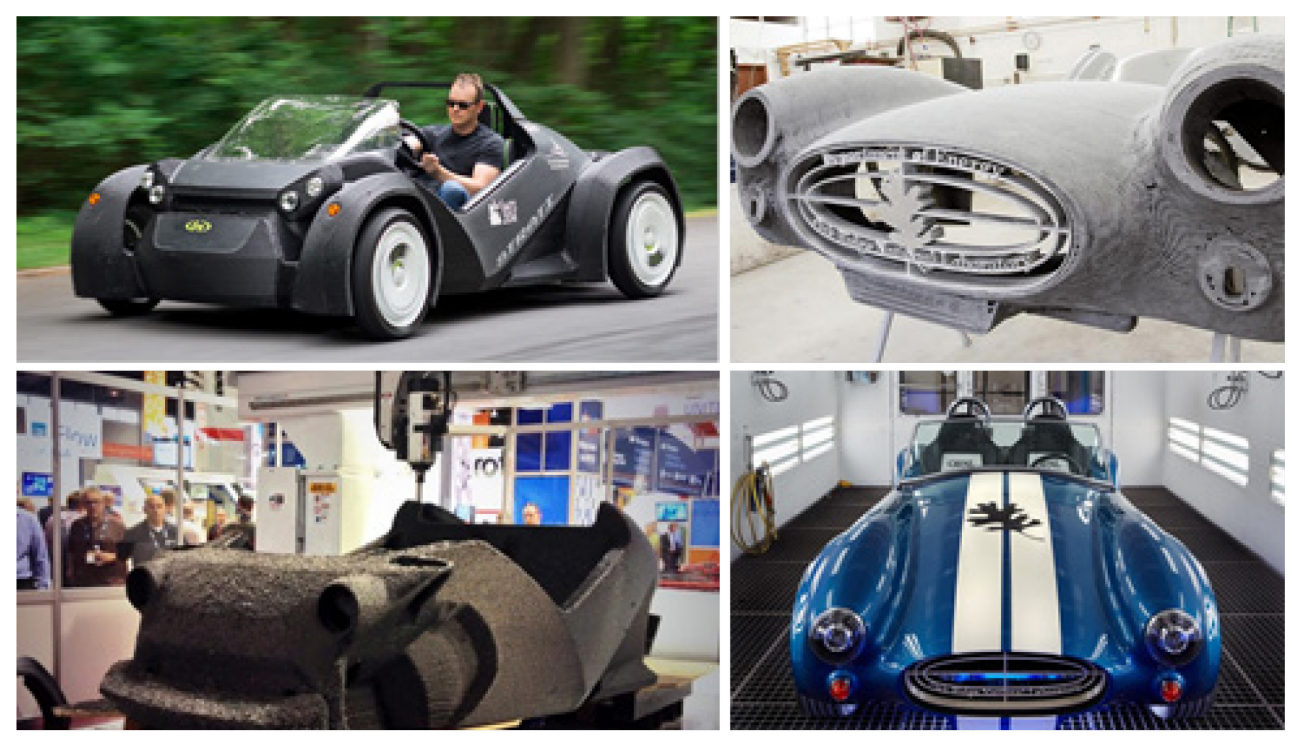

Fig. 7 - Strati, the first printed car (left) and Shelby Cobra printed replica (right) [12]

It is further estimated that in this car about 25,000 parts would be needed for the construction of this car through conventional methods rather than 49 parts through additive processes as constructed. In addition, the possibilities of customizing vehicles through additive processes do not encounter barriers in order to limit the geometries or general dimensions [22] defined at the time of production of the specific tools, namely the molds [23]. Ford built a replica of a Shelby Cobra (Fig. 7 , right) that they claimed it took 4 days to construct with a total cost of $3000 \$$, contrasting with the 4 months and 500.000\$ with conventional methods [12].

That is, by adapting the production and application of large additive manufacturing technologies, what will define the final price will be only the volume that is intended to be produced, without the influence of any change that is intended to be applied that does not imply an increase in the quantity of material needed [19]. 
As described earlier, D-Shape is a BAAM process of Binder Jetting with stone derived powders, thus being possible to present a strategy of reuse of materials that are generated in the extraction and production of stone [24], and this by-product is a problem for this industry, having here a solution for its reuse.

This point emerges pertinently at a time when we are living with ecological concern and awareness, with the adoption of strategies for the reduction and reuse of materials [25], as well as the analysis of the life cycle of the products in the design phase being increasingly important in an initial phase of a product development, the study of its life cycle approaching this in a circular economy philosophy [26].

At another level, we can also observe the advances of large additive manufacturing technologies used to build houses, using micro-reinforced cements. Seeing therefore a growing interest in the development of additive manufacturing technologies in order to scale up the resulting systems and products. As an example of this, we have Apis Cor, a Russian company that developed layer-bylayer systems to build houses, widely known for building a house in only $24 \mathrm{~h}$. This kind of solution changes the whole paradigm about house construction, as it makes possible to construct a house in much less time, witch almost zero waste and much less implications in terms of logistics.

However, one of the limitations of this type of processes for complex shapes is still the time of construction of the pieces that in a certain way make it impossible to apply. There is a broad set of factors such as feed rate optimization [27], inter- layer strength optimization [13] to be studied today as it is possible to observe in the literature.

However, factors such as the support material generated, in the case of pieces with greater geometric complexity, which will later be removed, adding deposition time, part removal and finishing operations of the surfaces where these structures are generated [28], make this a factor to take into account for the optimization of the process for large parts.

This subject will therefore be one of the objects of study in this article.

\section{Ecological Aspects}

This strategy of reusing materials taken as waste [29], resulting from operations of extraction, production and transformation of raw material and its application in the construction of products, add value to these materials, following the trend of a strategy that is aligned with the current trends of circular economy and life cycle study of products, meeting ecological strategies by reducing the production of virgin raw material and consequently of $\mathrm{CO} 2$ emissions, among other factors around this production of raw material.

In this document it is intended to bring further materials to be explored for BAAM applications based on reuse of industrial by-products among others similar that will be binded with the application of a binder agent.

These materials will be, for example, stone dust and wood waste resulting from the exploitation and transformation by industrial entities as well as tire granules, with tires being an environmental problem due to the enormous scale of production and annual waste in relation to the capacity of the tire itself [30,31], and there is still interest in exploring the characteristics of this material for various applications. Finally, other materials of interest will be the cork granulate, which is a high value material and can see in the BAAM systems a way to expand its range of application, thus increasing the interest and value of this material.

\section{New Approach to BAAM}

Context. As described above, the generation of support material is a multi-level waste in terms of construction time and the material itself being generated. To tackle this problem, we introduce a system concept based on an adjustable platform applied to a hybrid manufacturing system with material deposition and subtraction tools. 
Generally, the work platforms in additive manufacturing systems, in geometrical terms, are flat bases, and according to the geometry of the piece to be constructed, it will be necessary to generate support material that will recreate the shape of the surface of the final piece and at the end of the operation will be removed.

In this case, the concept proposal suggests that the platform itself be dynamic, adapting to the geometry of the part to be built, substantially reducing the amount of support material to be generated by streamlining the construction process and finishing operations.

This solution goes beyond changing the paradigm of the additive manufacturing system layer-bylayer deposition with support material, it intends to change the way one thinks about the production of large-sized parts of small series in the industry.

Taking as an example the urban furniture industry, since it perfectly aligns with the objectives of the concept, there are numerous advantages with the production of large pieces in small series of customized products tailored to the client, with the possibility of creating impossible geometries to recreate through conventional methods and also with the possibility of applying differentiating materials in its products in a philosophy of implementing products aligned with a circular economy with the reuse of industrial by-products, among others.
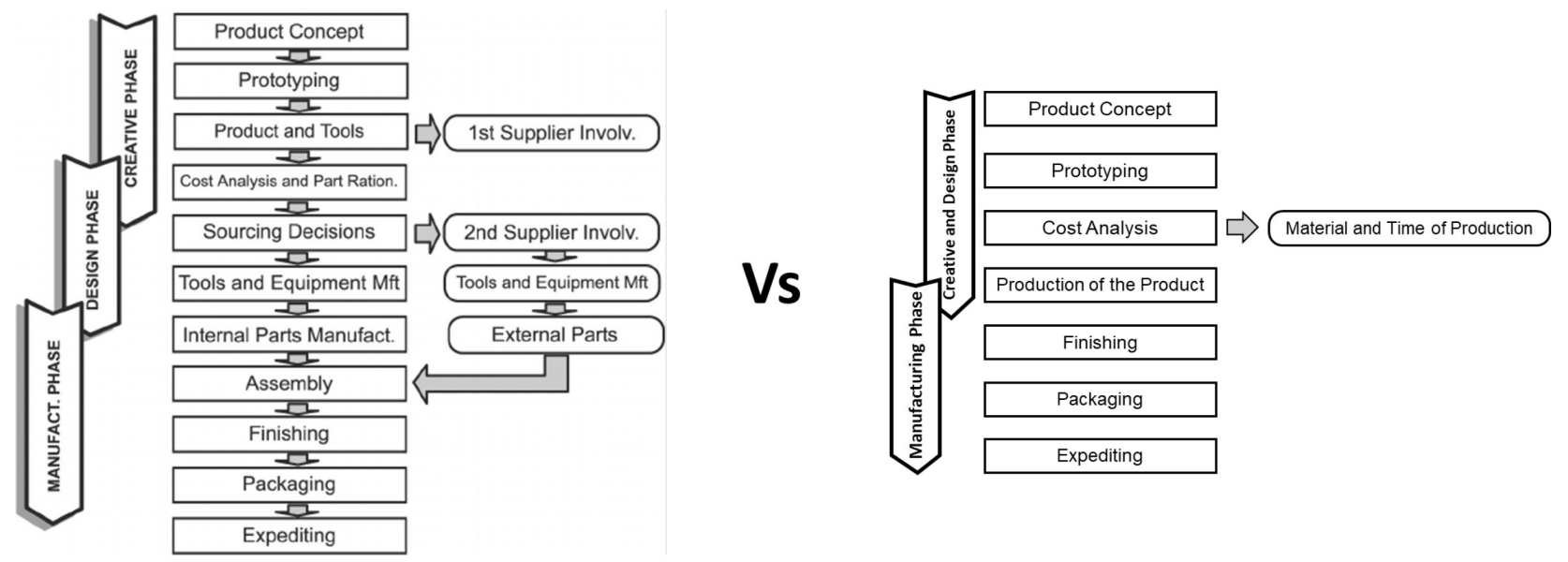

Fig. 8 - Workflow with conventional processes vs additive processes

As we can see in the figure above (Fig. 8), comparing the conventional flow chart of the different phases in a new product development methodology, with the implementation of new digital and flexible additive manufacturing systems, it is possible to shorten the number of phases, and the costs associated to these phases, and also its possible to reduce time and costs in the remaining phases. For in- stance, in the prototyping phase, to test the product and/or show it to a client, it's possible to have a first part in a short time without tooling costs associated. This makes it possible to create more prototypes, to explore more solutions for a given product. After producing the prototypes and validating the final solution, it's possible to have in short time a final product with costs only associated to materials and hour/machine, reducing costs and wasted material in tooling production. In the end of the process, it can be necessary or not to assemble the different parts, as it's possible to create a product with different parts already mounted in the construction process.

\section{Concept}

The system is then composed of a configurable platform built from a set of organized pins that allow its vertical displacement ( $Z$ axis), and also has a Cartesian robot system that allows the displacement (in $\mathrm{X}$ and $\mathrm{Y}$ ) of a replaceable tool where there will be the extrusion head which will make the deposition of the material, and finally there will be still curing systems of the material through forced convection and / or UV and IR light.

This set of organized pins that allow its configuration in height ( $\mathrm{Z}$ axis), and when entering the model of the part to be produced in the system, it will configure the height of the pins layer by layer, 
thus allows the deposition of the material on them and thus it will not be necessary to produce support material. This means that the platform itself recreates the shape of what would be the mold of the part, and in this way, the need for its creation is eliminated, making possible the production of parts in small series that, as described previously, may be unfeasible due to the cost and time of production of specific tools such as the mold.

In the figures below (Fig. 9 and Fig. 10) the system with adjustable platform is shown captioned.
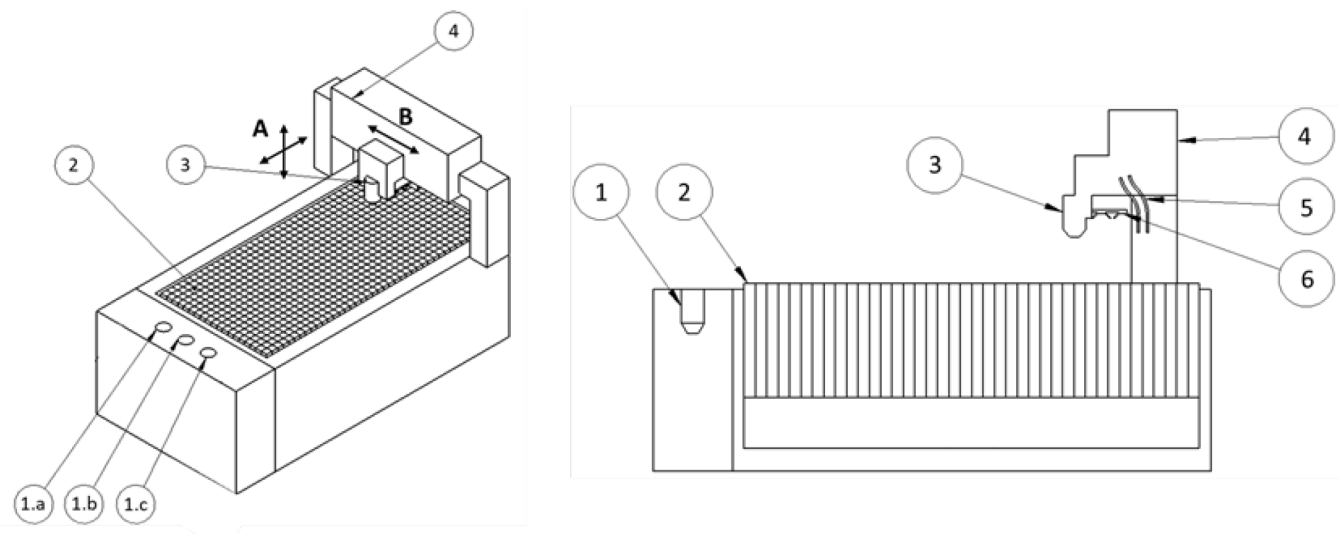

Fig. 9 - Concept schematic

Table 1 - System composition

\begin{tabular}{|c|l|}
\hline $1 . \mathrm{a}$ & Roughing tool \\
\hline $1 . \mathrm{b}$ & Extrusion tool (rough finish) \\
\hline $1 . \mathrm{c}$ & Extrusion tool (detail) \\
\hline 2 & Configurable platform (pin) \\
\hline 3 & Roughing/deposition tool \\
\hline 4 & X,Y and movement system \\
\hline 5 & Hot air projection system for the manufacturing surface \\
\hline 6 & UV light irradiation system or other \\
\hline
\end{tabular}

So, with this solution, to construct a given product, its possible do adapt the geometry of the work platform so it adjusts and recreates the surface of the part, reducing the time of construction and material waste as explained in the present document. In the image below (Fig. 11) it's possible to understand how the system will work during the process of construction of a part. 


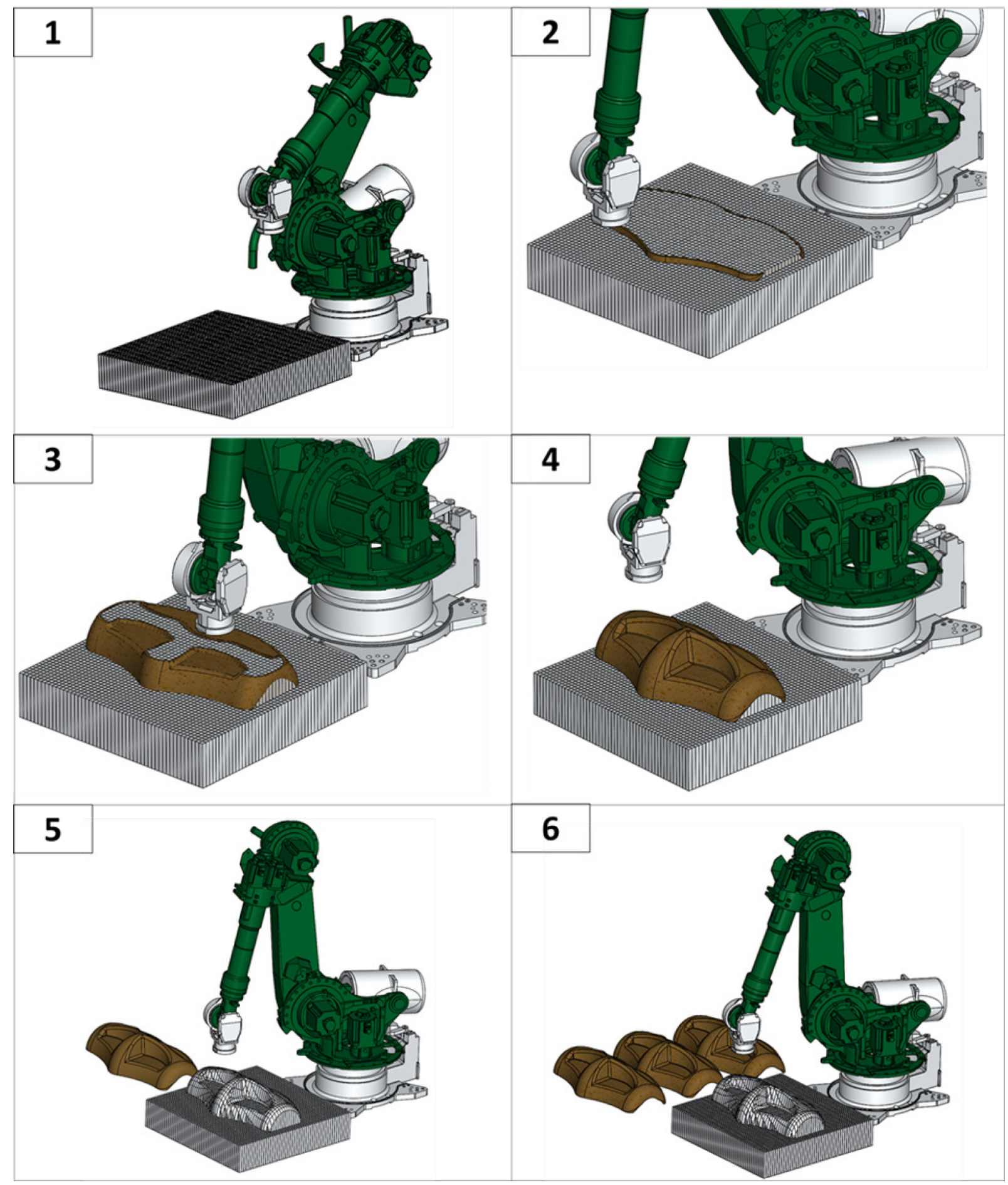

Fig. 10 - Schematic process [32]

As it's shown in the figure above, in step 1. the platform is leveled for the first layer, as the process goes (step 2) the pins move in Z-axis forming the surface of the part in that layer, and this process is repeated as shown in step 3. until we have the finished part as shown in step 4 that is removed as shown in step 5.

This method makes it even possible to take the part from the work platform when the construction ends, and restart again so it can produce continuously, as shown in step 6. 
Deposition system. In the development of the system under study in this article, several materials were developed and tested with different binders in order to validate their application.

Among these materials is the tire granulate on which is shown the image (Fig.11) below the scheme of premixing the material with a binder.

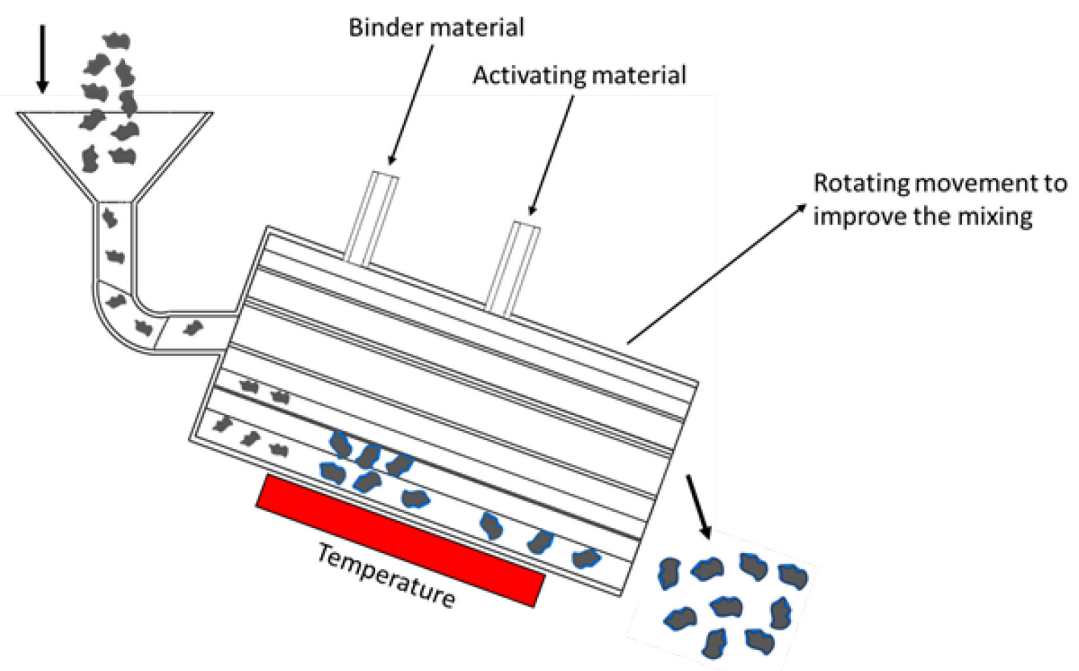

Fig. 11 - Material mixing system

This premix, made out of the deposition system, favors bonding at the time of deposition, expediting the mixing process on the deposition head and its bonding at the time of deposition.

At this stage the material is then mixed with the binder and upon mixing in the extrusion head and depositing it will bond as shown in the figure below (Fig. 12). After performing this premix, the material already has a certain amount of binder which will facilitate and accelerate the deposition and bonding process between layers.
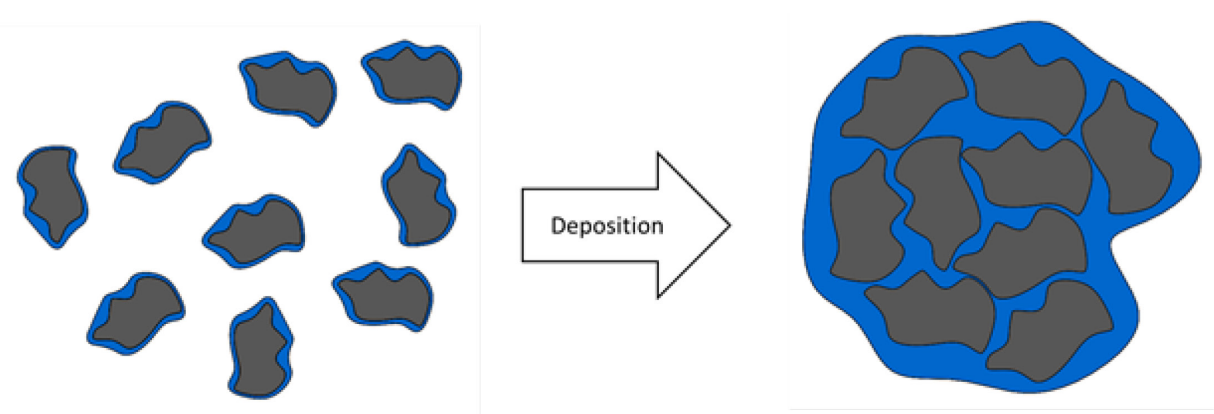

Fig. 12 - Material mixing scheme

For this type of materials based on granulates and application of binders, it was necessary to develop a system that allows to mix these 2 materials ensuring uniformity of the same at the exit of the extrusion head. For this purpose, a double spindle extrusion head is required which favors the mixing of the materials and is also able to deposit in a controlled manner based on the speed of rotation of the spindles. In this head also occurs the addition of binder material that ensures adhesion between the grains layer by layer. In the figure (Fig.13) below it is possible to see the operating scheme of the extrusion head. 

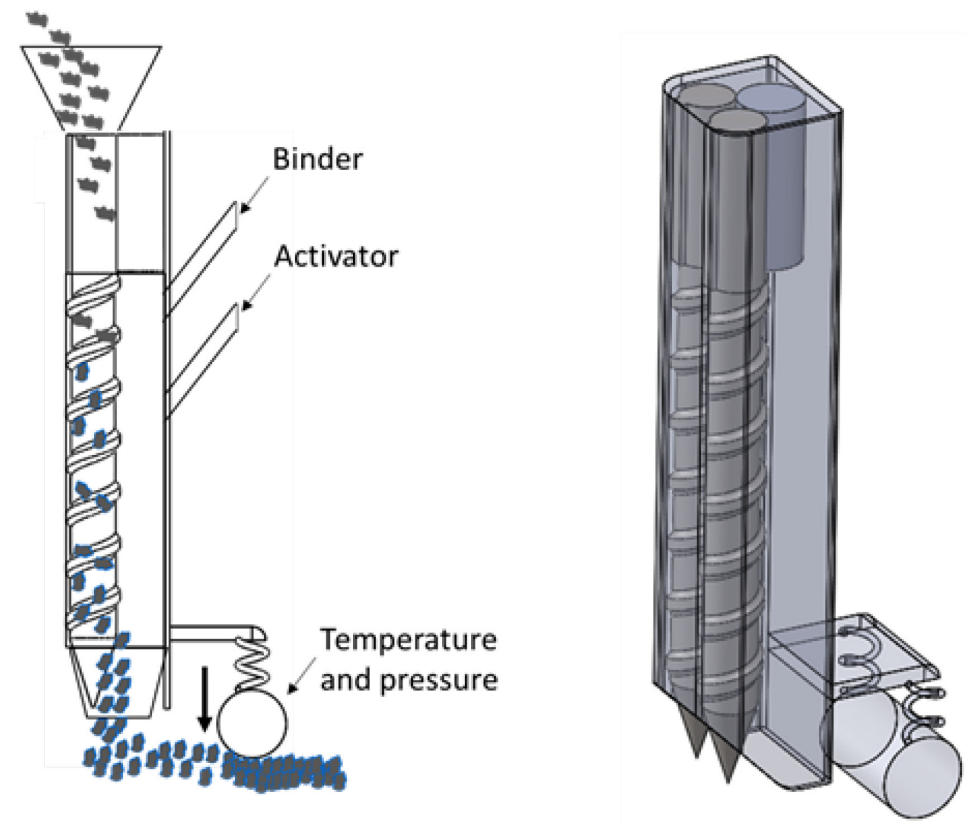

Fig. 13 - Extrusion system

As can be seen in the above schemes, at the time of deposition of the material, pressure is applied forming a dense layer ensuring a uniform distribution of the material, also guaranteeing the geometrical stability of the final part.

In the images below follow some of the tests performed with the materials in question, namely the tire granulates and its binder.

With this method, the objective will be to remove the piece in a "green" state at the end of the construction process, ie the bond between the particles must guaran- tee the geometrical stability of the piece during its construction, however as a final product, the objective the part must be impregnated with a binder that guarantees the use of the products without losing their shape or deterioration, having the purpose of enhancing the structure of the produced part.

This is done with the aim of optimizing the part process continuously in this type of BAAM systems, allowing the part to be constructed quickly, eliminating the support structures through the adjustable platform, and then this is removed from the platform for a healing zone, allowing the start of the process for a new part.

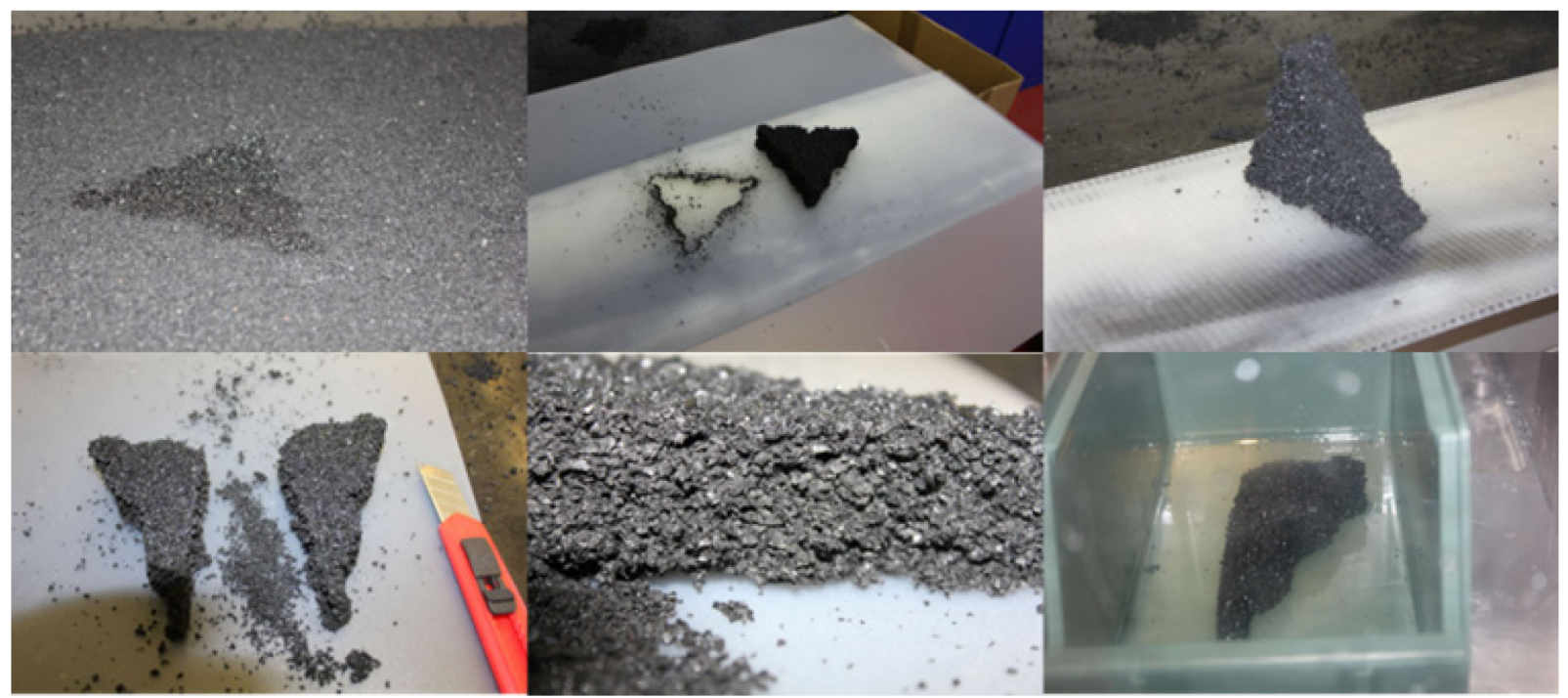

Fig. 14 - Material tests [31] 
It should be noted that the tests presented above represent small parts although this article deals with BAAM, however, this process was done manually, with application of systems of cure layer by layer, and therefore it is very difficult to construct a large part through the manual process.

This system also has the advantage of being able to apply different particle sizes during the process, this being possible through the feeding of 2 or more different extrusion systems, being fed with different materials and / or with different particle sizes, allowing to increase the density and consequently the strength of the resulting parts.

In the figure below (Fig. 15) it is possible to see by the step-by-step scheme the application of different material granulometry increasing the density of each layer.

As can be seen in the above scheme, in step 1 a layer is deposited, in step 2 there is place for the exchange of tool for deposition of material with different granulometry, which is deposited in step 3 , resulting in a layer with higher density as it is possible to see in step 4, and thereafter, the process repeats layer by layer. This kind of strategy can also be used for multi-material parts.

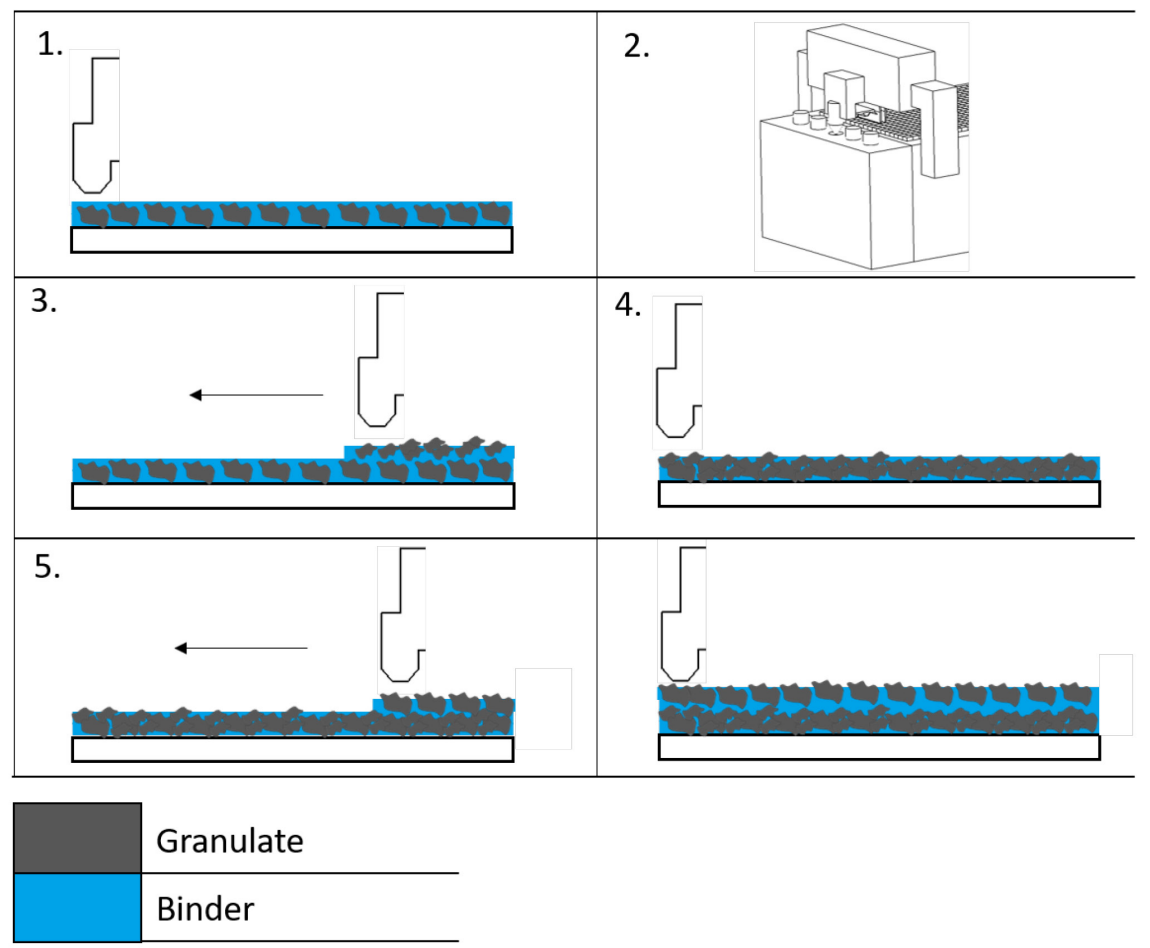

Fig. 15 - Deposition strategies

However, it is possible to conclude that with the materials under study, through an automated process that optimizes the different stages of deposition and curing of the material, the materials and process in question is perfectly feasible, this conclusion being drawn from the resulting part that be requested in different ways, it has maintained its geometry without loss of material.

System variations. In terms of surface finish, with the application of the adjustable platform, the surface of the piece to be constructed that is in contact with the pins will have a stairwell effect equivalent to that which the pins reproduce when organized in order to recreate the surface of the piece. This effect is reduced as much as the size of the pins used, however, by decreasing their size there will be a considerable increase in the number of pins, making the process more complex as the resolution of the pin is refined. However, this system presents several strategies to mitigate or cancel this effect.

For parts that do not need surface finishing, for example, inside it can be created in contact with the problem pins, if in the case of a good surface finish two different levels of complexity and level are presented surface finish. 
In a simpler solution for a finish that, however, does not present the best quality, one of the solutions will be to apply a membrane to the surface of the platform, being the pins when re-creating the shape of the piece, the transition between pins is disguised with this same membrane. In the figure below (Fig.16) it is possible to observe the application of this membrane and its advantages.

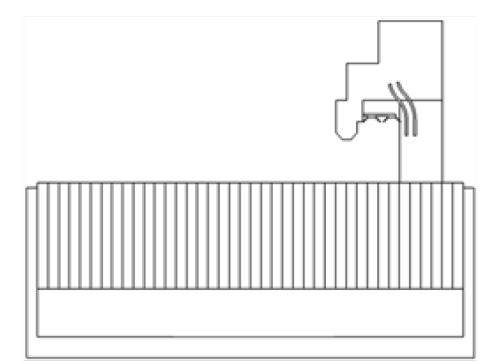

$1-$ Initial positioning

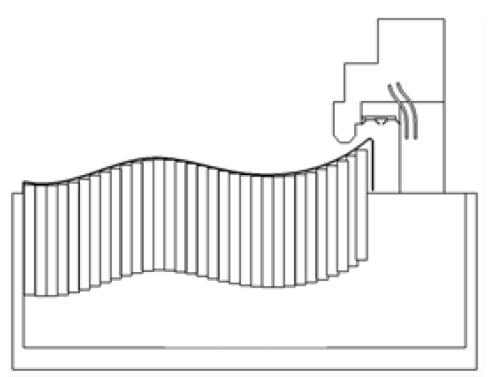

3 - Application of a leveling membrane

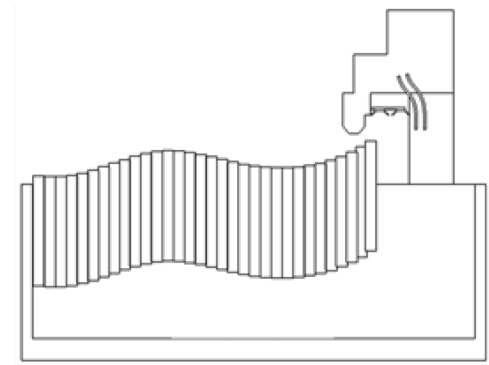

2 - Configured positioning

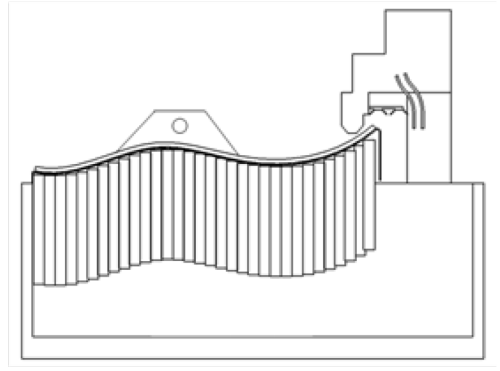

4-Production of the piece over the membrane

Fig. 16 - System concept scheme

In this the surface finish will show a great improvement compared to the general process without membrane application. In the figure (Fig. 17) below it is possible to perceive the expected difference of both solutions.

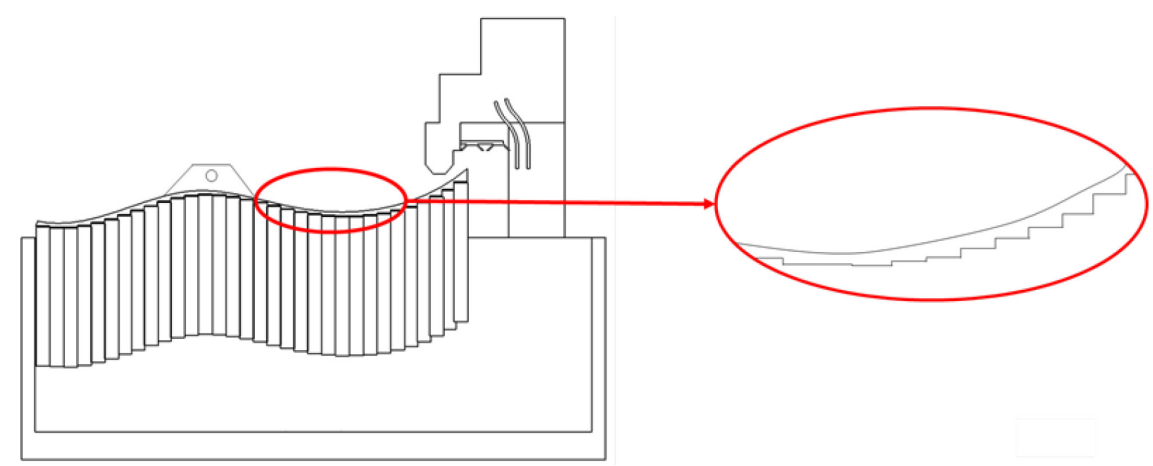

Figure 17: Finnishing effect with basic process

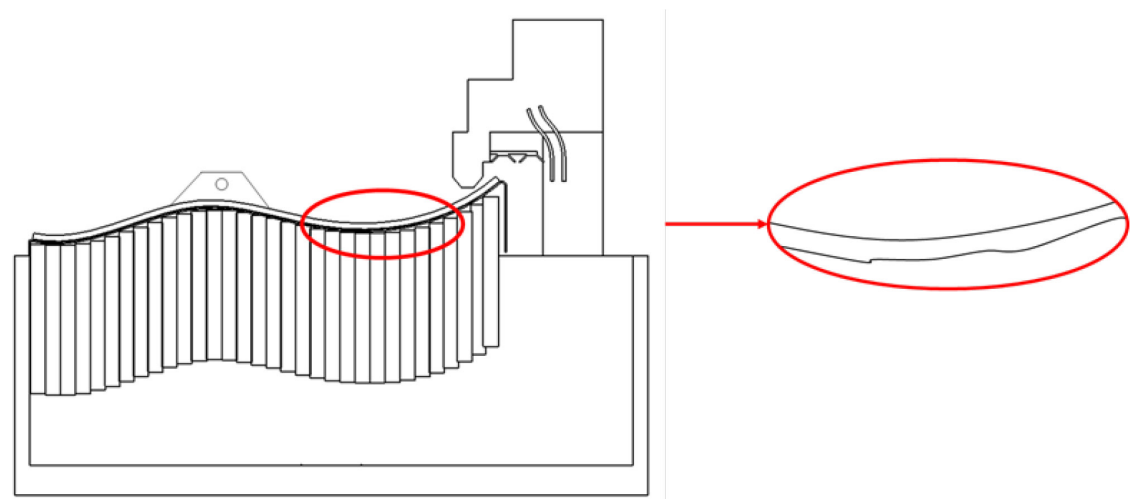

Fig. 17 - Finishing effect with membrane 
As described previously, the application of this membrane involves a further step in the process, making it more complex, and its application will be specific to the needs of the parts to be produced.

Thus, for a high-quality surface finish, the best but more complex solution will be the machining of the pins, thus forming the exact surface of the part to be con- structed. For this concept, it is foreseen the application of sacrificial tips at the top of the pins, which may be of different materials, possibly easier to machine.

That is, there will be an initial positioning of the pins according to the geometry of the part, followed by a subtraction operation on the top of these, thinning the deposition surface of the material. This process will involve the exchange of tools and a previous machining of the surface of the platform, making the process more time consuming and complex, however, for a high-quality finish, possibly for the production of a larger number of pieces, since there is reuse of the platform for the for the repetition of the process, making it more feasible for longer runs, this will be the best solution.

In the figures (Fig. 18 and Fig. 19) below it is possible to perceive the described process and the difference between surface finishing with and without the subtraction process of the pin surface.

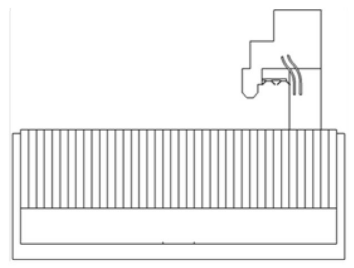

$1-$ Initial positioning

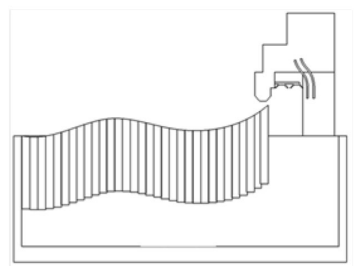

4 - Final surface

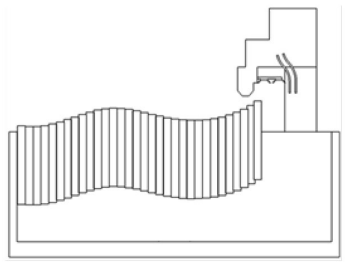

2 - Configurated platform

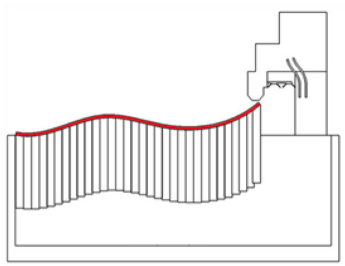

5 - Part production

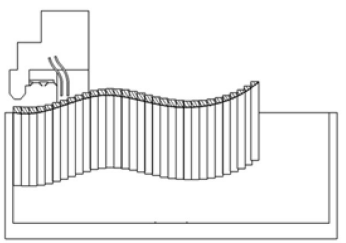

3 - Subtraction process

Fig. 18 - Subtraction process scheme

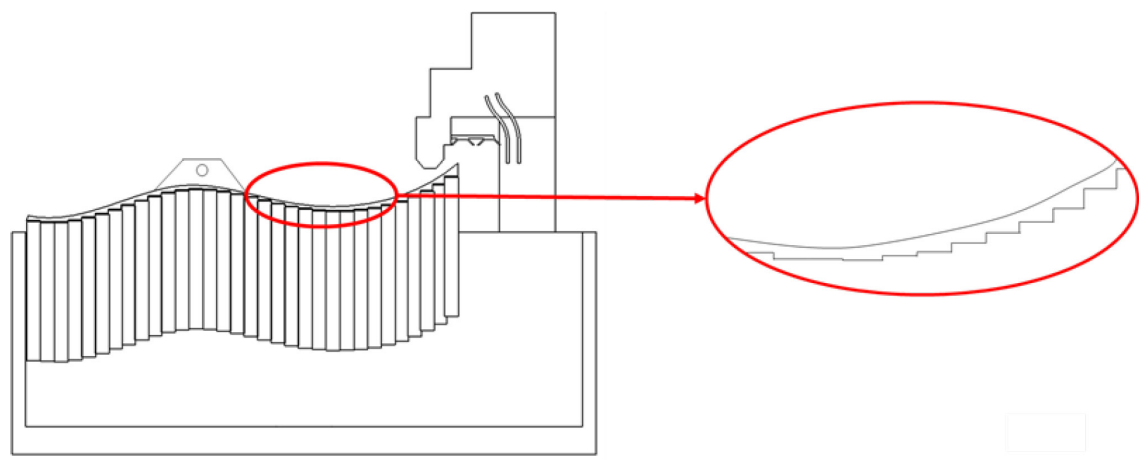

Fig. 19 - Finishing effect with basic process

It is possible to notice that this system has a great capacity to adapt to the needs of those who want to produce a large part without the generation of supports, with the need or not of high quality surface finish, and any of the solutions presented can be applied by the producer, that is, it will be an adaptation made at the time of production, without the need to purchase new equipment. 


\section{Conclusions}

Although it is at an early stage of the study, with no definitive conclusions to be drawn, trends and predictable paths are pointed out based on the evolution of today's industry, market and manufacturing processes.

As mentioned previously, in a perspective of sustainability and alteration of the industry paradigm, with a view to reducing waste generated, as well as the reintroduction of the same in the production cycle, applying it to the final products, the additive manufacturing presents itself as a viable response, still going against the current tendencies of the increasing increase of the need of individualized products, without neglecting the sustainability of the same ones

In addition, it is expected that medium-long term additive manufacturing technologies dominate certain sectors in the most diverse industries due to the numerous advantages they present, with a main focus on the ability to offer a single product without jeopardizing the alteration of production lines or loss of competitiveness in terms of the final cost of the product.

Therefore, for future work, it will be necessary to proceed with a prototype, possibly of smaller scale, for system validation, and after applying the necessary optimizations, then proceed to the development and construction of the individualized configuration system for automatic surface generation and apply the same to the large additive manufacturing system.

Concluding with this, in the future with the introduction of BAAM systems in the industry, there will be profound changes in the typology of everyday objects, which will only be possible through the study and development of optimization solutions that lead to the decrease of the time of manufacture of parts such as those developed in this article, and there is a need to explore these and many other solutions.

\section{Acknowledgements}

This work is supported by the Fundação para a Ciência e a Tecnologia (FCT) and Centro2020 through the Project references: UID/Multi/04044/2013; PAMI - ROTEIRO/0328/2013 (No 022158). The authors gratefully acknowledge OPTIMA companys support.

\section{References}

[1] Ugur M. Dilberoglu et al. "The Role of Additive Manufacturing in the Era of Industry 4.0". In: Procedia Manufacturing 11 (2017), pp. 545-554. ISSN: 23519789. DOI: 10.1016/j.promfg.2017.07.148.

[2] Robert Bogue. "3D printing: the dawn of a new era in manufacturing?" In: Assembly Automation 33.4 (2013), pp. 307-311. ISSN: 0144-5154. DOI: 10.1108/ AA - 06 - 2013 - 055.

[3] Wohlers Associates. 3D Printing and Additive Manufacturing State of the Industry, Annual 665 Worldwide Progress Report. Wohlers Associates, 2014. ISBN: 978-0-9913332-0-2.

[4] Terry Wohlers et al. Wohlers Report. 2017, p. 344. ISBN: 978-0-09913332-3-3.

[5] Tim Caffrey, Terry Wohlers, and R.I. Campbell. "Executive summary of the Wohlers Report 2016". In: (2016).

[6] I. Bártolo, P.; Gibson. "History of Stereolithographic Processes". In: (2011). DOI: 10.1007/9780- 387- 92904- 0 .

[7] Barry Berman. "3-D printing: The new industrial revolution". In: Business Horizons 55.2 (2012), pp. 155-162. ISSN: 00076813. DOI: 10 . 1016 / j . bushor . 2011.11.003.

[8] S. Scott Crump. "Apparatus and method for creating three-dimensional objects". In: (1989), US5121329 A. 
[9] C.R Deckard, J.J Beaman, and J.F Darrah. "Method for selective laser sintering with layerwise cross-scanning". In: (1990).

[10]Daniel R. Eyers and Andrew T. Potter. "Industrial Additive Manufacturing: A manufacturing systems perspective". In: Computers in Industry 92-93 (2017), pp. 208-218. ISSN: 01663615. DOI: 10.1016/j.compind.2017.08.002.

[11] Nannan Guo et al. "Additive manufacturing: technology, applications and research needs". In: Frontiers of Mechanical Engineering 8.3 (2013), pp. 215-243. ISSN: 2095-0233. DOI: 10.1007/s11465-013-0248-8.

[12] C.E; Duty, T; Drye, and A Franc. "Material development for tooling applications using big area additive manufacturing ( BAAM )”. In: ORNL Technical Re-port ORNL/TM-2015/78 (2015).

[13] Vidya Kishore et al. "Infrared preheating to improve interlayer strength of big area additive manufacturing (BAAM) components". In: Additive Manufacturing 14 (2017), pp. 7-12. ISSN: 22148604. DOI: 10.1016/j.addma.2016.11.008.

[14]Enrico Dini. "Method and apparatus for quick production of a conglomerate building structure". In: (2011).

[15] Jian-Yuan Lee, Jia An, and Chee Kai Chua. "Fundamentals and applications of 3D printing for novel materials". In: Applied Materials Today 7 (2017), pp. 120-133. ISSN: 23529407. DOI: 10 . $1016 /$ j . apmt . 2017.02 .004$.

[16] Jeffrey W. Stansbury and Mike J. Idacavage. "3D printing with polymers: Challenges among expanding options and opportunities". In: Dental Materials 32.1 (2016), pp. 54-64. ISSN: 01095641. DOI: 10.1016/j.dental.2015.09.018.

[17] Jamison Go et al. "Rate limits of additive manufacturing by fused filament fabrication and guidelines for high-throughput system design". In: Additive Manufacturing 16 (2017), pp. 1-11. ISSN: 22148604. DOI: 10.1016/j.addma.2017.03.007.

[18] Blaine Erickson Brownell. Transmaterial next: a catalog of materials that redefine our future, $p$. 314. ISBN: 9781616896218.

[19] Mohsen Attaran. "The rise of 3-D printing: The advantages of additive manufacturing over traditional manufacturing". In: Business Horizons 60.5 (2017), pp. 677-688. ISSN: 00076813. DOI: 10.1016/j.bushor.2017.05.011.

[20] Alessandro Abbà, Sabrina Sorlini, and Maria Cristina Collivignarelli. "Research experiences on the reuse of industrial waste for concrete production". In: 10001 (2017), pp. 1-8.

[21] Chun-Che Huang, Horng-Fu Chuang, and San-Yuan Chen. "Corporate Memory: Design to better reduce, reuse and recycle”. In: Computers \& Industrial Engineering 91 (2016), pp. 48-65. ISSN:03608352.DOI:10.1016/j.cie.2015.10.016.

[22] Lonnie J Love et al. "Breaking Barriers in Polymer Additive Manufacturing”. In: (2015), pp. 117.

[23] Mojtaba Khorram Niaki and Fabio Nonino. "Additive manufacturing management: a review and future research agenda". In: International Journal of Pro- duction Research 55.5 (2017), pp. 1419-1439. ISSN: 0020-7543. DOI: 10.1080/00207543.2016.1229064.

[24] X Xu et al. "Energy consumption model of Binder-jetting additive manufacturing processes". In: International Journal of . . 53.23 (2015), pp. 7005-7015. 
[25] Malte Gebler, Anton J M Schoot Uiterkamp, and Cindy Visser. "A global sustainability perspective on 3D printing technologies". In: Energy Policy 74 (2014), pp. 158-167. DOI: 10.1016/j.enpol.2014.08.033.

[26] Yunlong Tang, Kieran Mak, and Yaoyao Fiona Zhao. "A framework to reduce product environmental impact through design optimization for additive manufacturing". In: Journal of Cleaner Production 137 (2016), pp. 1560-1572. ISSN: 09596526. DOI: 10.1016/j.jclepro.2016.06.037.

[27] Ginger Gardiner. Big area additive manufacturing (BAAM): Increasing material feed and speed. 2015.

[28] Mary Kathryn Thompson et al. "Design for Additive Manufacturing: Trends, opportunities, considerations, and constraints". In: CIRP Annals - Manufacturing Technology 65.2 (2016), pp. 737-760. ISSN: 17260604. DOI: 10.1016/j.cirp. 2016. 05. 004. arXiv: arXiv: 1011 . 1669v3.

[29] Feisal Mohammed et al. "Identification of an environmentally friendly symbiotic process for the reuse of industrial byproduct - An LCA perspective". In: Journal of Cleaner Production 112.x (2016), pp. 3376-3387. ISSN: 09596526. DOI: 10.1016/j.jclepro.2015.09.104.

[30] S. Ramarad et al. "Waste tire rubber in polymer blends: A review on the evolution, properties and future". In: Progress in Materials Science 72 (2015), pp. 100- 140. ISSN: 00796425. DOI: 10.1016/j.pmatsci.2015.02.004.

[31]Chia Ching Chen et al. "Evaluation of the Waste Tire Resources Recovery Program and Environmental Health Policy in Taiwan". In: International Journal of Environmental Research and Public Health 6.3 (2009), pp. 1075-1094. ISSN: 16604601.DOI:10.3390/ijerph6031075.

[32] Ruben Silva, Eduardo Noronha, Vitor Neto and Artur Mateus. "New perspectives in the development of new products through additive manufacturing". In $7^{\text {th }}$ Meeting on PhD Design Research 